Unpublished letter in response to Hafri, A., \& Firestone, C. (2021). The perception of relations. Trends in Cognitive Sciences. DOI: 10.1016/j.tics.2021.01.006

\title{
Perceiving relations directly: An invitation
}

\author{
Guilherme Sanches de Oliveira ${ }^{1}$ and Anthony Chemero ${ }^{2}$ \\ ${ }^{1}$ Department of Psychology and Ergonomics, Technische Universität Berlin \\ ${ }^{2}$ Departments of Philosophy and Psychology, University of Cincinnati
}

April 5, 2021

There are some things you can just see; there are other things that you need to figure out by thinking. Theorizing in cognitive science has sometimes obscured this observation, for example in what Fodor [1] called "New Look Psychology", which took perception and cognition to be continuous. We are grateful to Hafri and Firestone for insisting that seeing and thinking are not the same thing. We are also grateful for their pointing out that, in fact, there are many more things that we can just see than most people realize, including surprisingly complex relations, like events and social interactions. As they put it, "a recent and growing body of work suggests that we do not only reason about such sophisticated relations in moments of deliberate reflection, but also see them directly, much as we see properties like shape, motion, or color." There is a longstanding tradition, from the very beginning of psychology as a distinct scientific discipline, that agrees that vision, and other forms of perception, are direct. So while Hafri and Firestone are certainly correct that there is a growing body of work supporting the direct perception of relations, they are incorrect to call it recent. Consideration of this longer tradition can not only strengthen their case but also help them avoid some puzzles and difficulties.

What does it mean to say that perception (of relations or whatever else) is direct? A useful perspective is offered by what Fodor [2] called the American naturalist approach in psychology, started well over a century ago by William James and further developed fifty years ago by James Gibson and by many others since (see e.g. [3,4]). In this naturalist view that we endorse, perception is direct in that it is the active attending to and becoming acquainted with the real world "out there" so to speak. The usual contrast, then, is with the view that our perceptual access to the world is mediated by internal representations, that we can 
know 'external stimuli' only via sensations or impressions. Directly perceiving is a matter of detecting and differentiating what's significant rather than constructing or inferring meaning through processing and interpreting sensory inputs. Perception, so conceived, is no longer an ill-posed problem [5], requiring prior knowledge and complex interpretation of sensory representations. See Box 1.

\section{BOX 1. American naturalism as radical empiricism}

The American naturalist tradition understands psychological phenomena in terms of the embodied adaptive activity of organisms in their environment:

- "Perceiving is an achievement of the individual, not an appearance in the theater of his consciousness. It is a keeping-in-touch with the world, an experiencing of things rather than a having of experiences" [5].

- "knowing is not a matter of making propositions about the environment. Knowings are just states of affairs at a psychological grain, and, like states of affairs at a biological grain, they must stand in some sort of adaptive relation to the environment" [3].

This is in line with the "radical empiricist" view that we directly perceive not only objects but also relations $[9,10]$. A prominent example is the perception of possibilities for action, i.e., affordances (see Fig 1.) Direct perception of the world includes unmediated access to, and non-inferential knowledge of, these relations.

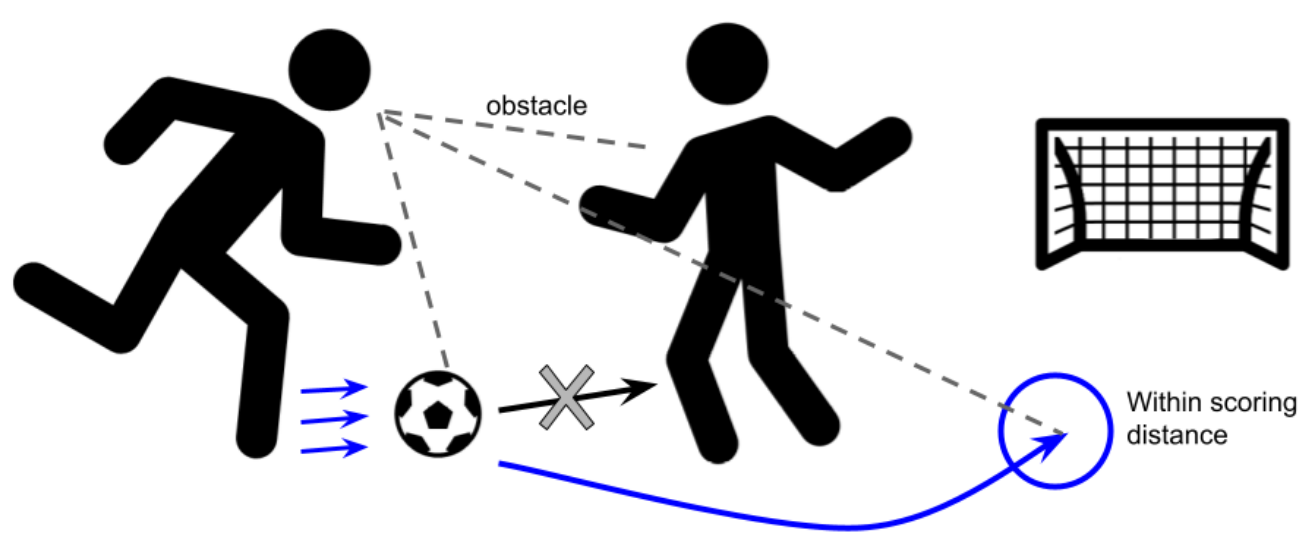

Figure 1. Directly perceivable relations include the affordance of kicking the ball in different ways, time-to-contact with the opponent, and the affordance of going around the opponent to get within scoring distance. The presence of teammates would establish additional relations (also directly perceivable). 
Hafri and Firestone propose that the perception of relations is direct, but it's not clear what they mean by this. In fact, their repeated references to perception as "representing" relations and "extracting" relational structure from the "visual scene" and the "retinal image" suggest they rely on a theory of perception that is paradigmatically 'indirect' in the usual sense of the term. We invite Hafri and Firestone to understand 'direct seeing' the way we do. If we understand 'direct' appropriately, many of the puzzles and outstanding questions that they identify have long been clarified and answered.

Consider, for instance, how Hafri and Firestone describe the perception of relations as seeming counterintuitive because "there is no component of the retinal image corresponding to" the relation. In the naturalist approach, perception (as direct) is not based on the retinal image or any other type of stimulation of sense organs, but amounts to the detection of invariant structure in the environment-and this is a difference that makes the supposed puzzle entirely unproblematic. A well-known example is the perception of imminent collision through the detection of $\tau$ (tau), the relational variable that specifies (optically or otherwise) time-to-contact and is used by many different animals, from birds to athletes [6]. And, speaking of athletes, one of the outstanding questions Hafri and Firestone identify is whether new and arbitrary relations can "come to be represented like more canonical perceptual relations" and they give the example of the relation "50 yards from" that, for an athlete, can mean "within field-goal range." This is precisely what, in the naturalist tradition, has long been understood as an affordance, i.e., a possibility for action that exists due to a relation between what the world is like and what the agent is like [7]. Crucially, a wealth of empirical evidence supports the view that affordances are perceived (rather than inferred) and directly so: we perceive affordances for ourselves, for others, for joint action, and even for assembling objects to create a tool with which to accomplish a task $[6,8]$.

Following in the American naturalist tradition allows us to understand the perception of relations as 'direct' in the usual sense of the term. It would also allow Hafri and Firestone to give firmer footing to their proposal while at the same time circumventing the puzzles and questions that the ill-posed, representationalist theory gives rise to.

\section{References}

1. Fodor, J. A. (1983). The modularity of mind. The MIT press.

2. Fodor, J. A. (1990) A theory of content and other essays. The MIT press.

3. Michaels, C. F., Carello, C. (1981) Direct perception. Prentice-Hall.

4. Heft, H. (2001) Ecological psychology in context: James Gibson, Roger Barker, and the legacy of William James's radical empiricism. Psychology Press. 
5. Warren, W. H. (2021) Information Is Where You Find It: Perception as an Ecologically Well-Posed Problem. i-Perception, 12(2), 1-24. DOI: 10.1177/20416695211000366.

6. Turvey, M. T. (2018) Lectures on perception: An ecological perspective. Routledge.

7. Gibson, J. J. (1979) The Ecological Approach to Visual Perception. Psychology Press.

8. Wagman, J. B., Blau, J. J., eds. (2019) Perception as Information Detection: Reflections on Gibson's Ecological Approach to Visual Perception. Routledge.

9. James, W. (1890) Principles of Psychology, Volumes 1 and 2. Henry Holt and Co.

10. James, W. (1909) Essays in Radical Empiricism. Longman, Green and Co. 